\title{
Momentum forcing of the quasi-biennial oscillation by equatorial waves in recent reanalyses
}

\author{
Y.-H. Kim and H.-Y. Chun \\ Department of Atmospheric Sciences, Yonsei University, Seoul, South Korea \\ Correspondence to: H.-Y. Chun (chunhy@yonsei.ac.kr)
}

Received: 12 January 2015 - Published in Atmos. Chem. Phys. Discuss.: 24 February 2015

Revised: 20 May 2015 - Accepted: 31 May 2015 - Published: 16 June 2015

\begin{abstract}
The momentum forcing of the QBO (quasibiennial oscillation) by equatorial waves is estimated using recent reanalyses. Based on the estimation using the conventional pressure-level data sets, the forcing by the Kelvin waves (3-9 $\mathrm{m} \mathrm{s}^{-1}$ month $^{-1}$ ) dominates the net forcing by all equatorial wave modes $\left(3-11 \mathrm{~m} \mathrm{~s}^{-1} \mathrm{month}^{-1}\right)$ in the easterly-to-westerly transition phase at $30 \mathrm{hPa}$. In the opposite phase, the net forcing by equatorial wave modes is small $\left(1-5 \mathrm{~m} \mathrm{~s}^{-1}\right.$ month $\left.^{-1}\right)$. By comparing the results with those from the native model-level data set of the ERA-Interim reanalysis, it is suggested that the use of conventional-level data causes the Kelvin wave forcing to be underestimated by $2-4 \mathrm{~m} \mathrm{~s}^{-1}$ month $^{-1}$. The momentum forcing by mesoscale gravity waves, which are unresolved in the reanalyses, is deduced from the residual of the zonal wind tendency equation. In the easterly-to-westerly transition phase at $30 \mathrm{hPa}$, the mesoscale gravity wave forcing is found to be smaller than the resolved wave forcing, whereas the gravity wave forcing dominates over the resolved wave forcing in the opposite phase. Finally, we discuss the uncertainties in the wave forcing estimates using the reanalyses.
\end{abstract}

\section{Introduction}

The quasi-biennial oscillation (QBO) is the predominant variability of the tropical stratosphere with periods of about 20-35 months (Baldwin et al., 2001). The QBO is most prominent in the zonal wind field, alternating between easterly and westerly. The alternating jets modulate interannual extratropical wave activities and impact on the strength of the polar stratospheric vortex (Holton and Tan, 1980; Watson and Gray, 2014). The QBO also induces the secondary meridional circulation (Plumb and Bell, 1982), which modulates the distribution of chemical species in the tropics and extratropics (Hilsenrath and Schlesinger, 1981; Li and Tung, 2014). For these reasons, it is important to understand and model the QBO. In practice, such modulations of the polar vortex and chemical species distributions cannot be reproduced by global models in which the QBO is not simulated.

The QBO is driven by equatorial waves interacting with the stratospheric mean flow (Lindzen and Holton, 1968; Holton and Lindzen, 1972). It is thought that these equatorial waves are mainly generated by tropical convection (e.g., Salby and Garcia, 1987; Garcia and Salby, 1987; Hayashi and Golder, 1997). Thus, realistic simulations of the QBO require a suitable parameterization of the convection, a spatial resolution that can resolve the large-scale equatorial waves, and an appropriate parameterization of unresolved-scale convective gravity waves. Recently, robust QBO signals (i.e., persistent oscillation with periods close to the observed values) have been generated in several general circulation models (e.g., Scaife et al., 2000; Giorgetta et al., 2002; Shibata and Deushi, 2005; Kim et al., 2013; Kawatani et al., 2014; Schirber et al., 2014; Richter et al., 2014; Aquila et al., 2014; Rind et al., 2014). However, the QBO simulated by each model exhibits different features (e.g., different vertical structures or period ranges). Furthermore, the forcings driving the QBO are model-dependent. For example, at $20 \mathrm{hPa}$, Giorgetta et al. (2006) showed that the large-scale (modelresolved) wave forcing is larger than the forcing produced by parameterized gravity waves (PGWs) in the easterly-towesterly transition (E-W) phase, whereas the PGW forcing is dominant in the westerly-to-easterly transition (WE) phase in the MAECHAM5 model. In contrast, in the HadGEM2 (Bushell et al., 2010; Kim and Chun, 2015) and 
CAM5 (Richter et al., 2014) models, the PGW forcing is dominant in both phases at this altitude. Therefore, it is necessary to quantitatively constrain the forcing due to equatorial waves based on observations, which motivates this study.

It is difficult to directly measure the momentum forcing due to equatorial waves from observations, as this requires the simultaneous measurement of horizontal and vertical winds. Instead, for the Kelvin and gravity waves, momentum forcing has been estimated from temperature measurements (and sometimes along with the zonal wind) given by radiosonde and satellites using gravity wave theory (e.g., Sato et al., 1997; Ern and Preusse, 2009; Alexander and Ortland, 2010; Ern et al., 2014). An alternative to estimations from measurements is to use reanalyses. In the equatorial lower stratosphere, the horizontal wind and temperature data from radiosonde observations are assimilated in the reanalyses, along with satellite-observed temperature data from after 1979. It should be noted, however, that the vertical velocity is poorly constrained in the reanalyses. This might result in a spread of estimated wave forcings between the reanalyses, along with many other factors (e.g., different assimilation processes).

This study aims to estimate the momentum forcing due to equatorial waves in the reanalysis data sets. The equatorial waves resolved in the reanalyses are classified into Kelvin, mixed Rossby-gravity, inertio-gravity, and Rossby waves, and the forcing from each wave type is estimated. In addition, the forcing by smaller-scale waves that are unresolved in the reanalyses is also estimated by comparing the resolved wave forcing with the total forcing required for the QBO progression.

\section{Data and method}

Four recent reanalyses are used: the ECMWF (European Centre for Medium-Range Weather Forecasts) Interim Reanalysis (ERA-I; Dee et al., 2011), Modern-Era Retrospective Analysis for Research and Applications (MERRA; Rienecker et al., 2011), Climate Forecast System Reanalysis (CFSR; Saha et al., 2010), and Japanese 55-year Reanalysis (JRA-55; Kobayashi et al., 2015). The resolutions of these reanalyses are presented in Table 1. The horizontal resolutions of the native models for these reanalyses range from 0.38 to $0.7^{\circ}$. The models have $10-13$ vertical levels between about 70 and $10 \mathrm{hPa}$. The reanalysis data sets are available for variables that are interpolated vertically to the conventional pressure $(p)$ levels (e.g., 100, 70, 50, 30, 20, 10, and $7 \mathrm{hPa}$ ) from the model levels. In this study, we use $p$-level data sets with horizontal resolutions reduced to around $2 \Delta_{\mathrm{h}}$, where $\Delta_{\mathrm{h}}$ is the native resolution of the model (see Table 1). Provided that the effective resolution of weather prediction models is typically coarser than $4 \Delta_{\mathrm{h}}$ (e.g., Skamarock et al., 2014), a horizontal resolution of $\sim 2 \Delta_{\mathrm{h}}$ is sufficient to analyze the equatorial waves resolved by these reanalyses. To
Table 1. Horizontal resolution of the native models and pressurelevel data sets for the four reanalyses used in this study, along with the number of vertical levels at $70-10 \mathrm{hPa}$.

\begin{tabular}{lcc}
\hline & $\begin{array}{r}\text { Model resolution } \\
\text { (number of levels at }\end{array}$ & \multicolumn{2}{c}{ Data resolution used } \\
& \multicolumn{2}{c}{ (0) $\mathrm{hPa})$} \\
\hline ERA-I & TL255 $\sim 0.7^{\circ}(10)$ & $1.5^{\circ}(5)$ \\
MERRA & $0.5^{\circ} \times 0.667^{\circ}(12)$ & $1.25^{\circ}(6)$ \\
CFSR & T382 $0.38^{\circ}(13)$ & $1.0^{\circ}(5)$ \\
JRA-55 & TL319 $\sim 0.56^{\circ}(10)$ & $1.25^{\circ}(5)$ \\
\hline
\end{tabular}

examine the sensitivity of the wave forcing estimation to the vertical level of the reanalysis data sets, we also use the native model-level data set of ERA-I. The temporal resolution of the data used is $3 \mathrm{~h}$ for MERRA and $6 \mathrm{~h}$ for the others. Additionally, we calculated the wave forcing estimates using 6-hourly subsampled MERRA data (not shown), and confirmed that the difference between the results from 3- and 6-hourly data is negligible. The data in all reanalyses cover the period 1979-2010.

The zonal momentum forcing due to stratospheric waves is calculated in the transformed Eulerian-mean (TEM) equation (Andrews et al., 1987):

$$
\begin{aligned}
\bar{u}_{\mathrm{t}} & =\bar{v}^{*}\left[f-(a \cos \phi)^{-1}(\bar{u} \cos \phi)_{\phi}\right]-\bar{w}^{*} \bar{u}_{z} \\
& +\left(\rho_{0} a \cos \phi\right)^{-1} \nabla \cdot \mathbf{F}+\bar{X} .
\end{aligned}
$$

The notation follows the conventions described in Andrews et al. (1987). Here, $\mathbf{F}=\left(F^{(\phi)}, F^{(z)}\right)$ is the Eliassen-Palm (E-P) flux, defined by

$$
\begin{aligned}
F^{(\phi)}= & \rho_{0} a \cos \phi\left(\bar{u}_{z} \overline{v^{\prime} \theta^{\prime}} / \bar{\theta} z-\overline{v^{\prime} u^{\prime}}\right), \\
F^{(z)}= & \rho_{0} a \cos \phi\left\{\left[f-(a \cos \phi)^{-1}(\bar{u} \cos \phi)_{\phi}\right]\right. \\
& \left.\overline{v^{\prime} \theta^{\prime}} / \bar{\theta}_{z}-\overline{w^{\prime} u^{\prime}}\right\} .
\end{aligned}
$$

The first term on the right-hand side of Eq. (1) is the sum of the Coriolis force and meridional advection, and the second term is the vertical advection. The third term represents the net momentum forcing by the waves resolved in the data. The term $\bar{X}$ represents any other zonal forcing, which can be obtained by subtracting the Coriolis force, the meridional and vertical advection, and the net resolved wave forcing from the zonal wind tendency (i.e., residual of the tendency equation). This term incorporates small-scale processes unresolved in the reanalysis, including mesoscale gravity waves and smaller-scale turbulent diffusion. It can also include resolved-scale waves if they are erroneously assimilated so that the other terms in Eq. (1) are under- or over-estimated. For example, it has been reported that the amplitude of the resolved-scale gravity waves in (re)analysis data sets is smaller than that of the observed waves with the similar scale (e.g., Schroeder et al., 2009), which may affect the estimates of not only the E-P flux forcing term but 
also $\bar{X}$. Equation (1), the TEM equation for pressure coordinates, is used for the model-level data set as well as for the $p$-level data sets, as the model level of ERA-I above $73 \mathrm{hPa}$ $(\sim 18 \mathrm{~km})$ is on the constant pressure level.

The momentum forcing produced by each of the equatorial modes can be calculated after separating the perturbations in Eqs. (2) and (3) into each wave mode, following Kim and Chun (2015, KC15 hereafter). The separation of wave modes is explained in detail in Sect. 4 of $\mathrm{KC15}$, and is briefly described here. The perturbation variables are split into symmetric and anti-symmetric components with respect to the Equator, and each component is transformed to the zonal wavenumber-frequency $(k-\omega)$ domain. In the symmetric spectrum, the perturbations for the Kelvin waves are restricted to $0<k \leq 20$ and $\omega<0.75$ cycle day $^{-1}$, and those for the mixed Rossby-gravity (MRG) waves are restricted to $|k| \leq 20$ and $0.1 \leq \omega \leq 0.5$ cycle day $^{-1}$ in the anti-symmetric spectrum. In this paper, the MRG waves refer to both the westward and eastward propagating $n=0$ waves. The two equatorial modes are further restricted in the spectral components $(k, \omega)$ by requiring $\left|F^{(z, H)}\right|<\left|F^{(z, M)}\right|$ (Kelvin waves) and $F^{(z, H)} F^{(z, M)}<0$ (MRG waves) (see KC15), where $F^{(z, H)}$ and $F^{(z, M)}$ are the contributions of the meridional heat flux and vertical momentum flux to $F^{(z)}$ (i.e., the first and second terms on the right-hand side of Eq. 3), respectively, for a given $(k, \omega)$. Spectral components that are not defined as Kelvin or MRG waves are classified as Rossby waves if $|k| \leq 20$ and $\omega \leq 0.4$ cycle day $^{-1}$, and as inertiogravity (IG) waves otherwise. After separating the perturbations into the four wave modes, the forcing is calculated by $\left(\rho_{0} a \cos \phi\right)^{-1} \nabla \cdot \mathbf{F}^{\mathrm{W}}$, where $\mathbf{F}^{\mathrm{W}}$ represents the E-P flux due to each mode.

\section{Results}

\subsection{Momentum forcing by the waves resolved in the reanalyses}

The time-height cross sections of the forcing by equatorial waves, averaged over $5^{\circ} \mathrm{N}-5^{\circ} \mathrm{S}$ regions, are shown in Fig. 1 , where model-level data from ERA-I have been used for recent years (2003-2010). For all figures in this paper except Fig. 5, the ticks on the horizontal axis correspond to 1 January of the given years. The eastward forcing by the Kelvin waves appears in the QBO phase of strong westerly shear. The MRG waves induce westward forcing in both phases of the westerly and easterly shear, with comparable magnitudes between the phases (Kawatani et al., 2010a, b, and KC15). The MRG wave forcing is primarily by the westward propagating mode not only in the easterly shear but also in the westerly shear (not shown), which may suggest the possibility of stratospheric generation of the wave above the easterly jet (see Maury and Lott, 2014, and KC15). For the Kelvin and MRG waves, the altitude and magnitude of the maximum
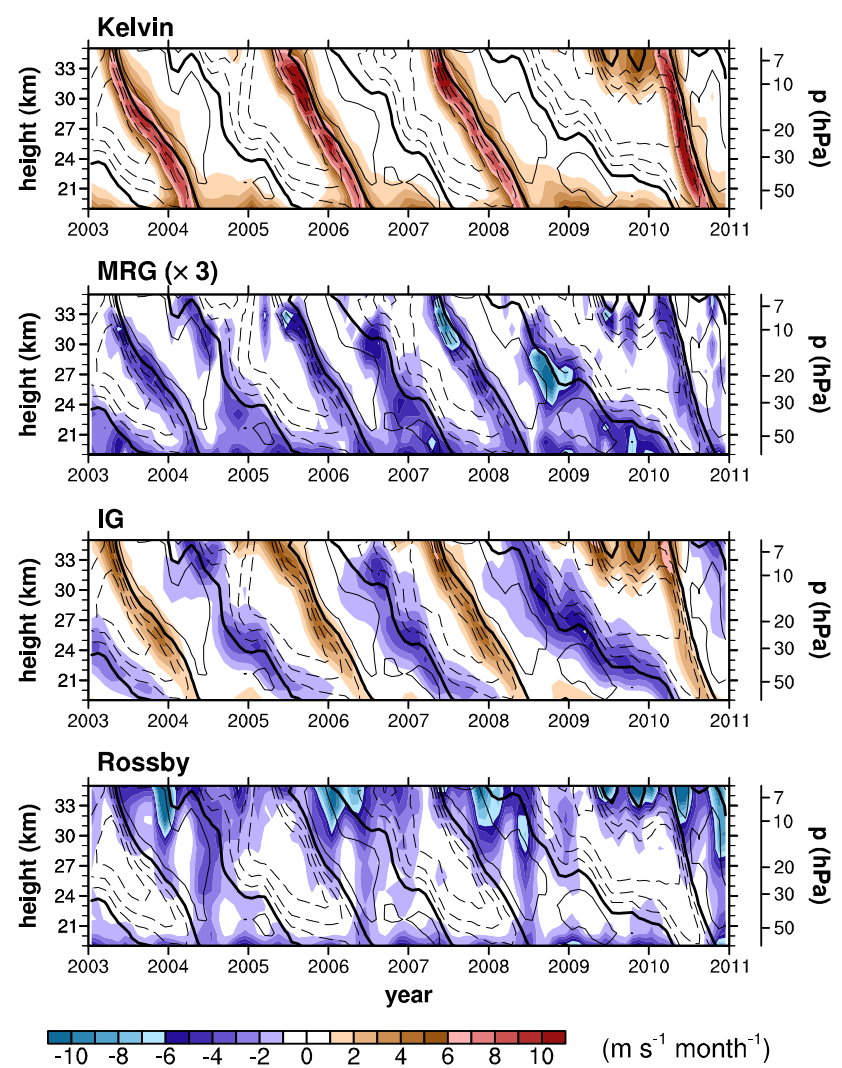

Figure 1. Time-height cross sections of the zonal momentum forcing by the Kelvin, MRG, IG, and Rossby waves (from top to bottom) averaged over $5^{\circ} \mathrm{N}-5^{\circ} \mathrm{S}$, obtained using the model-level data of ERA-I over the period 2003-2010 (shading). The MRG wave forcing is multiplied by 3 . The zonal mean wind over $5^{\circ} \mathrm{N}-5^{\circ} \mathrm{S}$ is superimposed at intervals of $10 \mathrm{~ms}^{-1}$ (contour). The thin solid, dashed, and thick solid lines indicate westerly, easterly, and zero wind, respectively.

forcing in each QBO cycle vary significantly. The IG waves provide eastward and westward forcing in the westerly and easterly shear phases, respectively. The Rossby wave forcing is strong in the upper stratosphere. Unlike the other waves, the Rossby wave forcing is not aligned with the strong-shear phases of the QBO at altitudes below $30 \mathrm{~km}$. Rather, it has significant magnitudes in the northern winters and summers and is weakened in the following seasons. In addition, this forcing does not appear in the strong easterlies of the QBO, as the Rossby waves do not propagate easily with the easterly background wind. These features in the vertical structure of the equatorial wave forcing are generally similar between the reanalysis data sets (not shown). Here, we select three levels, 50,30 , and $10 \mathrm{hPa}$, to assess the wave forcing in the reanalyses in detail. Note that the level of $10 \mathrm{hPa}$ is close to the upper limit of the sonde sounding assimilated to the reanalyses.

Figure 2 shows the zonal forcing given by the Kelvin, MRG, IG, and Rossby waves at $30 \mathrm{hPa}$ in 1979-2010, as obtained using the $p$-level data of the four reanalyses, as well 


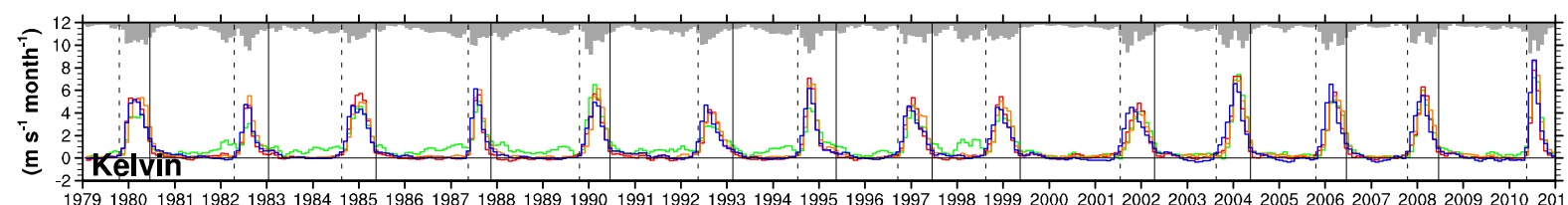

197919801981198219831984198519861987198819891990199119921993199419951996199719981999200020012002200320042005200620072008200920102011
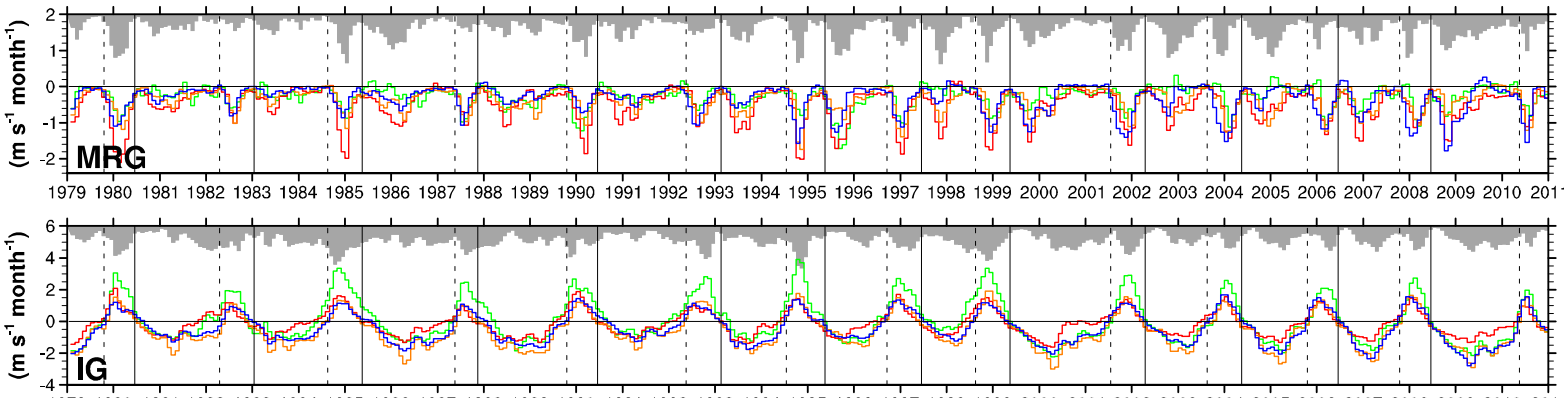

197919801981198219831984198519861987198819891990199119921993199419951996199719981999200020012002200320042005200620072008200920102011
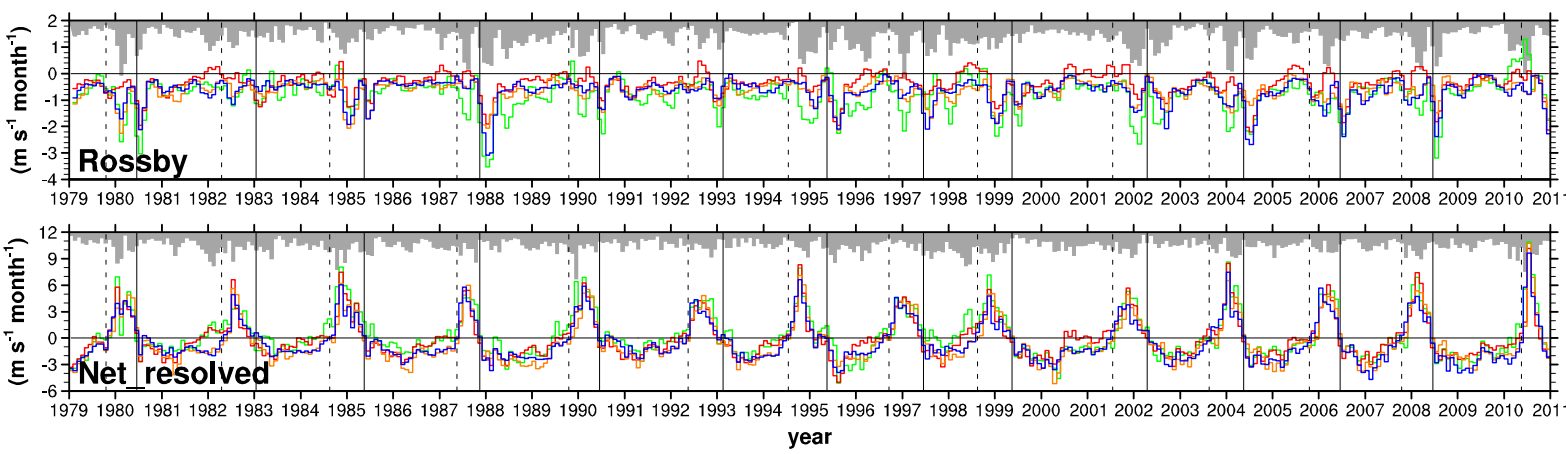

ERA-I

MERRA

CFSR

JRA-55

Figure 2. Zonal momentum forcing by the Kelvin, MRG, IG, and Rossby waves averaged over $5^{\circ} \mathrm{N}-5^{\circ} \mathrm{S}$ at $30 \mathrm{hPa}$ for the period $1979-2010$, as well as the net forcing by all resolved waves (from top to bottom) obtained using the $p$-level data of ERA-I (blue), MERRA (red), CFSR (green), and JRA-55 (orange). The phase of the maximum easterly and westerly in each QBO cycle at $30 \mathrm{hPa}$ is indicated by the dashed and solid vertical lines, respectively. The difference between upper and lower bounds of the wave forcing calculated from each data set is also indicated (gray shading).

as the net forcing due to all resolved waves. The spread between the four reanalyses (i.e., the difference between upper and lower bounds of the wave forcing estimated from each data set) is also indicated (gray shading). The phases of the maximum easterly (westerly) in each QBO cycle at $30 \mathrm{hPa}$ are indicated by the dashed (solid) vertical lines in Fig. 2. The temporal evolution of the equatorial wave forcing is, at the first order, consistent between the data sets. The peak magnitude of the Kelvin wave forcing in the E$\mathrm{W}$ phase shows similar cycle-to-cycle variations in all reanalyses. For instance, the Kelvin wave forcing in the four reanalyses is strong in $2010\left(7.1-8.7 \mathrm{~m} \mathrm{~s}^{-1}\right.$ month $\left.^{-1}\right)$ and weak in $1992\left(2.8-4.7 \mathrm{~m} \mathrm{~s}^{-1}\right.$ month $^{-1}$; here, the month in the unit of forcing refers to 30 days regardless of the month). Prior to around 1993, the MRG wave forcing in the reanalyses seems relatively sporadic and weak compared to afterward, although the forcing in 1980 and 1985 has exceptionally large peaks in MERRA. The magnitude of the MRG wave forcing reaches $\sim 2 \mathrm{~m} \mathrm{~s}^{-1} \mathrm{month}^{-1}$. The IG wave forcing varies between -3 and $4 \mathrm{~m} \mathrm{~s}^{-1}$ month $^{-1}$, follow- ing the QBO phase. The Rossby wave forcing magnitude is less than or similar to $\sim 2 \mathrm{~m} \mathrm{~s}^{-1}$ month $^{-1}$ in most years, except in 1980, 1988, and 2008 for CFSR and ERA-I (3$\left.3.5 \mathrm{~m} \mathrm{~s}^{-1} \mathrm{month}^{-1}\right)$. The net wave forcing has large positive peaks in the E-W phases $\left(3.4-11 \mathrm{~m} \mathrm{~s}^{-1}\right.$ month $\left.^{-1}\right)$, due mainly to the Kelvin waves, and is negative during the $\mathrm{W}-$ E phases $\left(1.5-5.2 \mathrm{~ms}^{-1}\right.$ month $\left.^{-1}\right)$ by the IG, MRG, and Rossby waves (Fig. 2). The peak forcing ranges during the E-W and W-E phases are summarized for each wave in Table 2 .

Although the evolution of the wave forcing is generally consistent between the reanalyses, some robust differences in forcing magnitude are shown in Fig. 2. The positive peaks of the IG wave forcing are always larger in CFSR than in the other data sets, and the Rossby wave forcing tends to be larger in CFSR and ERA-I than in MERRA and JRA-55. There are differences between the reanalyses of up to about $2 \mathrm{~m} \mathrm{~s}^{-1}$ month $^{-1}$ for the Kelvin, IG, and Rossby waves, and about $1 \mathrm{~m} \mathrm{~s}^{-1} \mathrm{month}^{-1}$ for the MRG waves (Fig. 2). The difference in the net wave forcing is up 


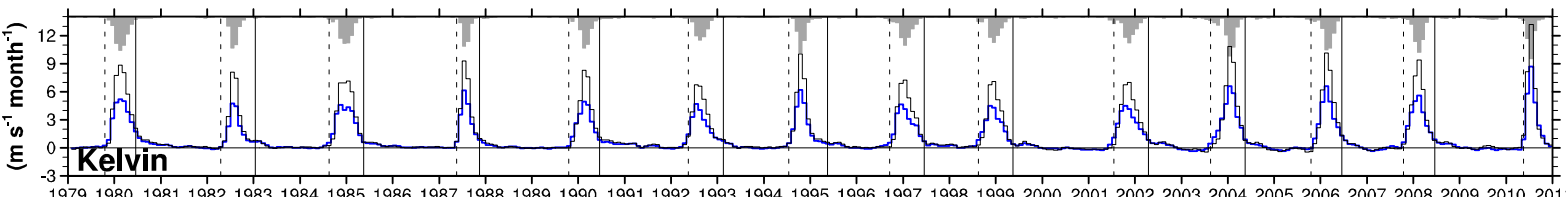

197919801981198219831984198519861987198819891990199119921993199419951996199719981999200020012002200320042005200620072008200920102011

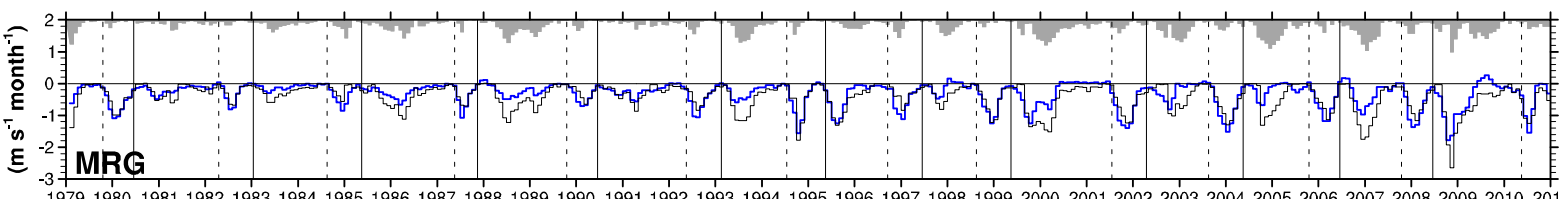

197919801981198219831984198519861987198819891990199119921993199419951996199719981999200020012002200320042005200620072008200920102011

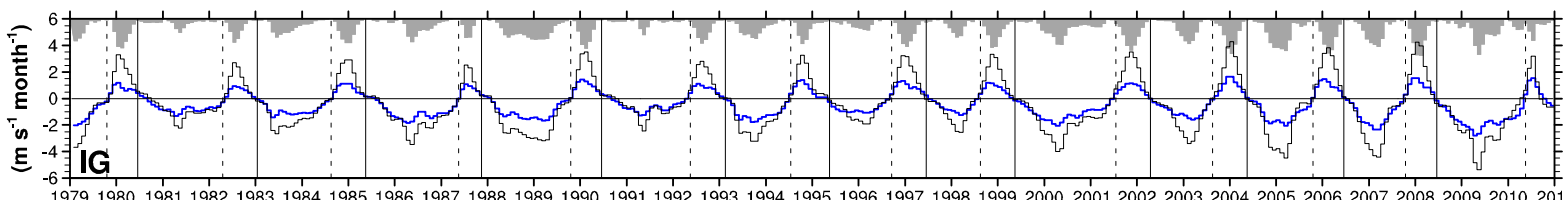

197919801981198219831984198519861987198819891990199119921993199419951996199719981999200020012002200320042005200620072008200920102011

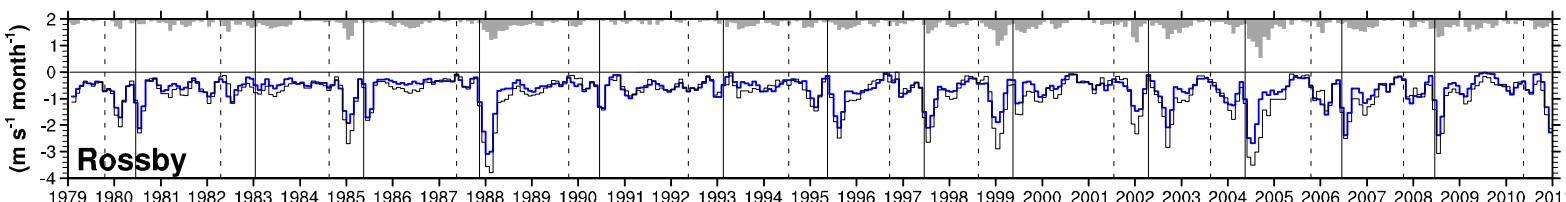

197919801981198219831984198519861987198819891990199119921993199419951996199719981999200020012002200320042005200620072008200920102011

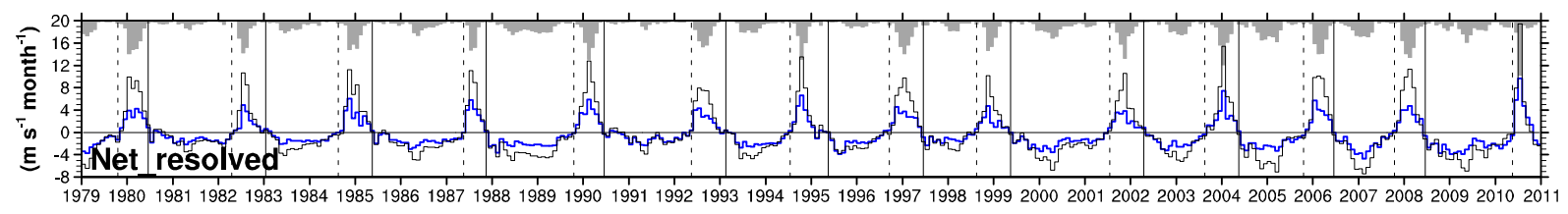

year

Figure 3. The same as in Fig. 2, except using the model-level data (black) along with the $p$-level data (blue) for ERA-I.

to about $4 \mathrm{~m} \mathrm{~s}^{-1}$ month $^{-1}$. There are many potential causes for this spread of forcing magnitudes between the reanalyses. For instance, each reanalysis used a different assimilation method, assimilated different observational data, and essentially used a different forecast model (e.g., in terms of model dynamics and resolutions). In addition, the species and numbers of assimilated observational data for a single reanalysis are dependent on time, particularly the satellite data. This makes the further investigation of temporal variations in wave forcing complicated. Therefore, in this study, we focus on assessing the range of wave forcing revealed by the reanalyses and do not speculate on the causes of the spread, or temporal variations, in the reanalyses.

Figure 3 shows the wave forcing at $30 \mathrm{hPa}$ calculated using the model-level data of ERA-I (ERA-I_ml) along with that using the $p$-level data of ERA-I. The plot exhibits robust differences in Kelvin and IG wave forcing between the two data sets. The peaks of the Kelvin wave forcing in the E-W phase from ERA-I_ml range from 6.7 to $13 \mathrm{~m} \mathrm{~s}^{-1}$ month $^{-1}$, which are $2-4 \mathrm{~m} \mathrm{~s}^{-1}$ month $^{-1}$ larger than those from ERAI. The IG wave forcing from ERA-I_ml has positive and negative peaks that are $0.8-2.7 \mathrm{~m} \mathrm{~s}^{-1}$ month $^{-1}$ larger than those from ERA-I. The differences in the MRG and Rossby wave forcing depend on the year and are typically less than $\sim 1 \mathrm{~m} \mathrm{~s}^{-1}$ month $^{-1}$. The net wave forcing in the E-W (W-
E) phase is $4-9 \mathrm{~m} \mathrm{~s}^{-1} \mathrm{month}^{-1}\left(1-4 \mathrm{~m} \mathrm{~s}^{-1}\right.$ month $\left.^{-1}\right)$ larger in the model-level result than in the $p$-level output.

The differences in forcing magnitude between the two ERA-I data sets are mainly a result of the vertical interpolation process. When perturbations in the model-level data are interpolated to the $p$ levels, those parts of waves with short vertical wavelengths are inevitably damped. For example, when a $p$ level is centered between two model levels, waves with a vertical wavelength of $2 \Delta_{\mathrm{V}}$ are totally filtered out by the interpolation, where $\Delta_{\mathrm{V}}$ is the vertical spacing between the two model levels. The filtering rate of waves with larger vertical wavelengths depends on the interpolation method. Waves with a wavelength of $4 \Delta_{\mathrm{V}}$ will be filtered at a rate of $50 \%$ in terms of their variance under linear interpolation, although this will decrease if a higher-order method is used. Given that $\Delta_{\mathrm{V}}$ in the lower stratosphere is approximately $1.4 \mathrm{~km}$ in ERA-I, waves with vertical wavelengths shorter than about $5.6 \mathrm{~km}$ might be significantly damped in the ERA-I $p$-level data. These wavelengths are close to the lower bound of the dominantly observed Kelvin waves (6$10 \mathrm{~km}$ ) and MRG waves (4-8 km) (Andrews et al., 1987). It is important that radiative damping, which induces the wave forcing in the atmosphere, is more prevalent in short verticalscale waves (e.g., Fels, 1982; Krismer and Giorgetta, 2014) than in longer waves that may be contained in both data sets. 
(a)

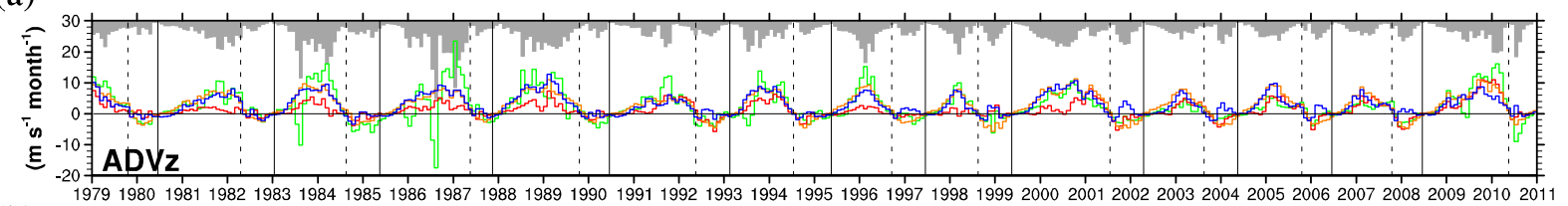

(b)

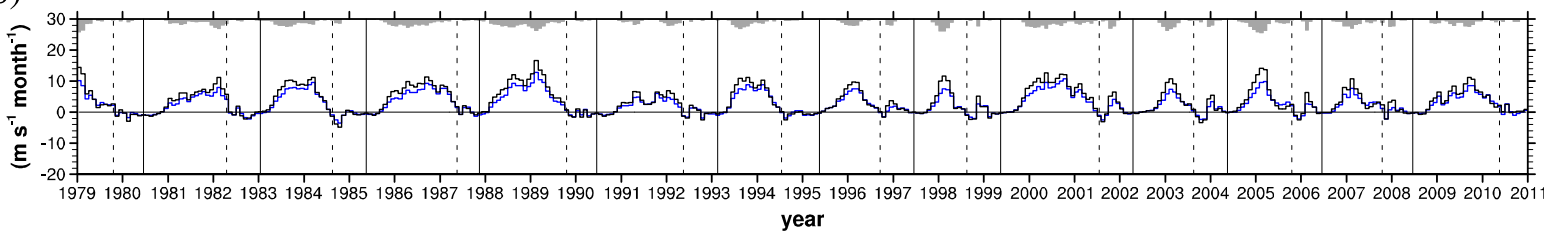

ERA-I

MERRA

CFSR

JRA-55

ERA-I_ml

Figure 4. The same as in (a) Fig. 2 and (b) Fig. 3, except for the vertical advection of zonal wind.

Table 2. Phase-maximum magnitudes of the Kelvin, MRG, IG, and Rossby wave forcing, net-resolved wave forcing, $\bar{X}$, and $\bar{X}^{*}$ $\left[\mathrm{ms}^{-1}\right.$ month $\left.^{-1}\right]$ at $30 \mathrm{hPa}$ in the E-W and W-E phases for the period 1979-2010, obtained using the $p$-level data sets and the ERA-I model-level data set. Details of $\bar{X}$ and $\bar{X}^{*}$ can be found from the text along with Eqs. (1) and (4). Positive forcing is denoted by bold font.

\begin{tabular}{llllll}
\hline & \multicolumn{2}{c}{ E-W } & & \multicolumn{2}{c}{ W-E } \\
\cline { 2 - 3 } \cline { 5 - 6 } & $p$-level & model-level & & $p$-level & model-level \\
\hline Kelvin & $\mathbf{2 . 8 - 8 . 7}$ & $\mathbf{6 . 7 - 1 3}$ & & & \\
MRG & $0.6-2.1$ & $0.6-1.8$ & & $0.2-1.8$ & $0.6-2.6$ \\
IG & $\mathbf{0 . 9 - 3 . 9}$ & $\mathbf{2 . 5 - 4 . 3}$ & & $0.6-3.0$ & $1.9-5.4$ \\
Rossby & $0.7-2.7$ & $0.6-2.9$ & & $0.7-3.5$ & $0.9-3.8$ \\
Net-resolved & $\mathbf{3 . 4 - 1 1}$ & $\mathbf{8 . 0 - 1 9}$ & & $1.5-5.2$ & $3.3-7.5$ \\
$\bar{X}$ & $\mathbf{5 . 8 - 1 7}$ & $\mathbf{3 . 1 - 1 1}$ & & $6.6-21$ & $11-18$ \\
$\bar{X}^{*}$ & $\mathbf{5 . 8 - 1 4}$ & & & $11-21$ & \\
\hline
\end{tabular}

This results in substantial differences between the two data sets, as shown in Fig. 3. The same may also be true for the other reanalyses. Unfortunately, not all the reanalyses provide model-level data sets. However, the vertical resolution of the native models in the lower stratosphere is comparable across all reanalyses (Table 1). Thus, the magnitude of the wave forcing obtained from the $p$-level data sets of reanalyses other than ERA-I (Fig. 2) should also be considered as underestimated, potentially by amounts comparable to those in ERA-I.

\subsection{Estimated momentum forcing by the waves unresolved in the reanalyses}

As mentioned in Sect. 2, the term $\bar{X}$ in Eq. (1) represents the zonal forcing by unresolved mesoscale gravity waves and turbulent diffusion, and is also influenced by the resolvedscale processes that are erroneously represented in the reanalyses. If one assumes that the resolved-scale processes are well represented in the reanalyses, the forcing by unre- solved processes can be approximated as $\bar{X}$. In this section, we calculate the vertical advection of zonal wind (the second term on the right-hand side of Eq. (1), ADVz hereafter) and estimate the range of $\bar{X}$ in the reanalyses. A discussion of the above assumption is included in the next section.

Figure 4a shows $\mathrm{ADV} z$, obtained using the $p$-level data of the four reanalyses. The peak magnitude of $\mathrm{ADVz}$ in the W-E phase is around $10 \mathrm{~m} \mathrm{~s}^{-1} \mathrm{month}^{-1}$, and that in the $\mathrm{E}-\mathrm{W}$ phase is typically $1-4 \mathrm{~m} \mathrm{~s}^{-1} \mathrm{month}^{-1}$ (excluding the anomalously large peaks in 1983 and 1986-1987 in CFSR). Note that ADVz in the W-E phase is much larger than the net-resolved wave forcing in the same phase (1.5$5.2 \mathrm{~m} \mathrm{~s}^{-1}$ month $^{-1}$; Table 2), and the two terms have opposite signs. There exist some robust ADVz features in the $\mathrm{W}-$ E phase: $A D V z$ is very similar in ERA-I and JRA-55, and ADVz in MERRA is about half of that in ERA-I or JRA-55 in many years. As a result, the spread between the reanalyses is quite large $\left(\sim 10 \mathrm{~m} \mathrm{~s}^{-1}\right.$ month $\left.^{-1}\right)$ in this phase (Fig. 4a).

The large spread in the W-E phase between the different reanalyses suggests that the ADVz values obtained from the reanalyses are highly uncertain. Moreover, it is speculated that this spread may result in a large spread in $\bar{X}$, as will be seen later. Therefore, the difference in ADVz between the reanalyses is further investigated by comparing $\bar{w}^{*}$ and the vertical shear of zonal wind $\left(\bar{u}_{z}\right)$. Figure 5a shows the climatologies of $\bar{w}^{*}$ obtained from each data set. The profiles of $\bar{w}^{*}$ from ERA-I and JRA-55 are in good agreement. However, below $30 \mathrm{hPa}, \bar{w}^{*}$ in MERRA is much smaller than in the other data sets, and that in CFSR is much larger than in the others above $10 \mathrm{hPa}$. The profiles of $\bar{w}^{*}$ in ERA-I show only slight differences between the $p$ - and model-level data. In previous studies by Niwano et al. (2003) and Schoeberl et al. (2008), the annual-mean ascent rate was inferred from the observed $\mathrm{H}_{2} \mathrm{O}$ to be about $0.26-0.35 \mathrm{~mm} \mathrm{~s}^{-1}$ near $30 \mathrm{hPa}$. In Fig. $5 \mathrm{a}, \bar{w}^{*}$ at $30 \mathrm{hPa}$ in ERA-I, CFSR, and JRA-55 is within this range of values. The smaller value of $\bar{w}^{*}$ in MERRA 

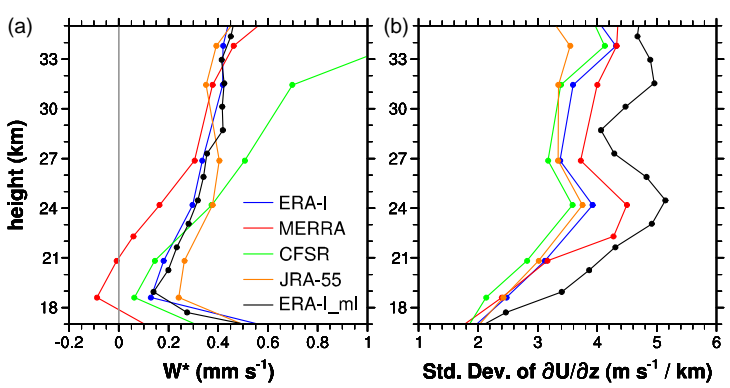

Figure 5. (a) Mean residual vertical velocity and (b) standard deviation of the monthly and zonal mean wind shear for the period 1979 2010 averaged over $5^{\circ} \mathrm{N}-5^{\circ} \mathrm{S}$, obtained using the $p$-level data of ERA-I (blue), MERRA (red), CFSR (green), and JRA-55 (orange) as well as the model-level data of ERA-I (black).

causes ADVz to be underestimated (see Fig. 4a) and contributes to the large spread of ADVz.

Figure $5 \mathrm{~b}$ shows the standard deviation of $\bar{u}_{z}$ obtained from each reanalysis data set. These values are governed by the magnitude of $\bar{u}_{z}$ that alternates between positive and negative with the QBO phase. Note that the difference in monthly and zonal mean wind between the reanalyses is small (not shown). Therefore, $\bar{u}_{z}$ is mainly dependent on the intervals between the $p$ levels. The standard deviation of $\bar{u}_{z}$ in ERA-I, CFSR, and JRA-55 is similar, as they have the same $p$ levels. MERRA has one more $p$ level, at $40 \mathrm{hPa}$, and thus the magnitude of $\bar{u}_{z}$ near $40 \mathrm{hPa}$ in MERRA is larger than in the others. In all of the reanalyses, the limited sampling across vertical levels causes the magnitude of $\bar{u}_{z} \mathrm{ob}-$ tained from the $p$-level data sets to be underestimated compared to $\bar{u}_{z}$ from the model-level data (Fig. 5b). This implies that, as for the wave forcing, the ADVz values from the $p$ level data sets should also be considered as underestimations. The ADVz obtained from ERA-I_ml is presented in Fig. 4b. It can be seen that ADVz in the W-E phase from ERA-I_ml is consistently $2-4 \mathrm{~m} \mathrm{~s}^{-1}$ month $^{-1}$ greater than that from the $p$-level data. Although this magnitude of difference between the $p$ - and model-level data seems small in Fig. $4 \mathrm{~b}$, it can have a significant effect in the estimation of $\bar{X}$ which has typical values of $\sim 10 \mathrm{~m} \mathrm{~s}^{-1}$ month $^{-1}$ as will be shown later. The Coriolis force and meridional advection terms in Eq. (1) are generally small near the equatorial lower stratosphere (not shown).

Figure 6a shows the value of $\bar{X}$ at $30 \mathrm{hPa}$ obtained from the $p$-level data sets of the reanalyses. The positive peaks of $\bar{X}$ in the $\mathrm{E}-\mathrm{W}$ phase range from 5.8 to $17 \mathrm{~m} \mathrm{~s}^{-1}$ month $^{-1}$, and the negative peaks in the $\mathrm{W}-\mathrm{E}$ phases vary from 6.6 to $21 \mathrm{~m} \mathrm{~s}^{-1}$ month $^{-1} \cdot \bar{X}$ in the $\mathrm{E}-\mathrm{W}$ phase is about $50 \%$ larger than the net resolved wave forcing (3.4-11 m s${ }^{-1}$ month $^{-1}$ ), and that in the W-E phase is much larger than the net resolved wave forcing $\left(1.5-5.2 \mathrm{~m} \mathrm{~s}^{-1} \mathrm{month}^{-1}\right)$. The spread in $\bar{X}$ between the reanalyses is up to $10 \mathrm{~m} \mathrm{~s}^{-1} \mathrm{month}^{-1}$, except in 1983 and 1986-1987, when the ADVz in CFSR has ab- normally large peaks (Fig. 4a). The large spread in $\bar{X}$ could be expected because of the large spread in ADVz (Fig. 4a). From Fig. 5a, we can see that a large portion of the spread in ADVz is due to the underestimated vertical velocity in MERRA. Additionally, the zonal wind shear is underestimated in all of the $p$-level data sets. Therefore, we attempt to partly correct the estimates of $\bar{X}$ via an additional calculation $\left(\bar{X}^{*}\right)$. In this calculation, ERA-I_ml is considered as reference data for all the terms in Eq. (1), except for the wave forcing term. $\bar{X}^{*}$ is estimated as

$$
\begin{aligned}
\bar{X}^{*} & =\left\{\bar{u}_{\mathrm{t}}-\bar{v}^{*}\left[f-(a \cos \phi)^{-1}(\bar{u} \cos \phi)_{\phi}\right]+\bar{w}^{*} \bar{u}_{z}\right\}^{\mathrm{r}} \\
& -\left(\rho_{0} a \cos \phi\right)^{-1} \nabla \cdot \mathbf{F},
\end{aligned}
$$

where a superscript $r$ denotes terms calculated using the reference data, and the E-P flux divergence term is calculated using the respective reanalyses. $\bar{X}^{*}$ is plotted in Fig. 6 b. The negative peaks of $\bar{X}^{*}$ in the W-E phase are larger than those of $\bar{X}$ by $5-12 \mathrm{~m} \mathrm{~s}^{-1}$ month $^{-1}$, particularly for MERRA. The changes in positive peaks do not appear to be large. The spread in $\bar{X}^{*}$ is up to $\sim 4 \mathrm{~ms}^{-1}$ month $^{-1}$, which results from the spread in resolved wave forcing (see Eq. 4). Finally, $\bar{X}^{*}$ in ERA-I_ml is shown in Fig. 6c. The positive peaks of $\bar{X}^{*}$ in the E-W phase in ERA-I_ml are 3.1$11 \mathrm{~m} \mathrm{~s}^{-1}$ month $^{-1}$, and the negative peaks in the W-E phase are $11-18 \mathrm{~m} \mathrm{~s}^{-1}$ month $^{-1}$. These values of $\bar{X}^{*}$ are comparable with those estimated by Ern et al. (2014). The positive peaks are smaller than those of the Kelvin wave forcing, suggesting that the peak magnitudes of the net mesoscale gravity wave forcing in the $\mathrm{E}-\mathrm{W}$ phase at $30 \mathrm{hPa}$ might be smaller than those of the Kelvin wave forcing. In contrast, the large negative values of $\bar{X}^{*}$ suggest that gravity waves are the dominant contributors to $\mathrm{QBO}$ in the $\mathrm{W}-\mathrm{E}$ phase, assuming that the turbulent diffusion is not of comparable magnitude. These results are consistent with those from previous studies using mechanistic, general circulation, or mesoscale models (e.g., Dunkerton, 1997; Giorgetta et al., 2006; Evan et al., 2012).

The wave forcing estimates at 50 and $10 \mathrm{hPa}$ are also presented in Tables 3 and 4, respectively. From Tables $2-4$, it is shown that the Kelvin wave forcing in the E-W phase tends to increase with height from $2.7-9.2 \mathrm{~m} \mathrm{~s}^{-1}$ month $^{-1}$ at $50 \mathrm{hPa}$ to $2.2-15 \mathrm{~m} \mathrm{~s}^{-1}$ month $^{-1}$ at $10 \mathrm{hPa}$, and the IG wave forcing from $0.5-2.5$ to $0.5-6.2 \mathrm{~m} \mathrm{~s}^{-1}$ month $^{-1}$. The Rossby wave forcing exhibits an abrupt change between 30 and $10 \mathrm{hPa}$, and it reaches $14 \mathrm{~m} \mathrm{~s}^{-1}$ month $^{-1}$ at $10 \mathrm{hPa}$ in the W-E phase (see also Fig. 1). $\bar{X}^{*}$ depends significantly on the height, so that it is twice as large at $10 \mathrm{hPa}$ as at $50 \mathrm{hPa}$ in both phases. This may reflect an increase in mesoscale gravity wave forcing at $10 \mathrm{hPa}$ in both phases of the QBO. However, it should be noted that the spread in resolved wave forcing, ADVz, and $\bar{X}^{*}$ at $10 \mathrm{hPa}$ across all reanalyses is $2-3$ times larger than that at $30 \mathrm{hPa}$ (not shown), implying less reliability of the forcing estimates at this altitude. This result might be due to fewer constraints acting on the wind and temperature fields 
(a)

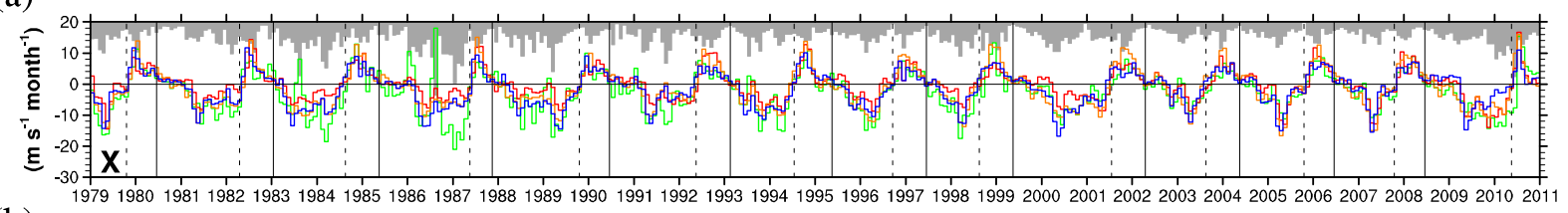

(b)

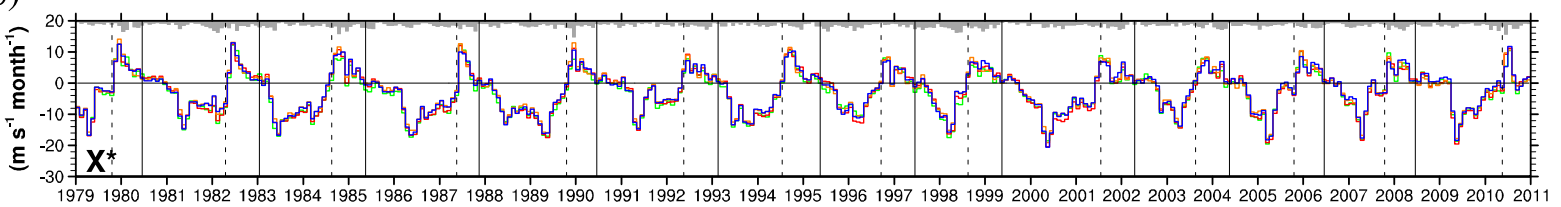

(c)

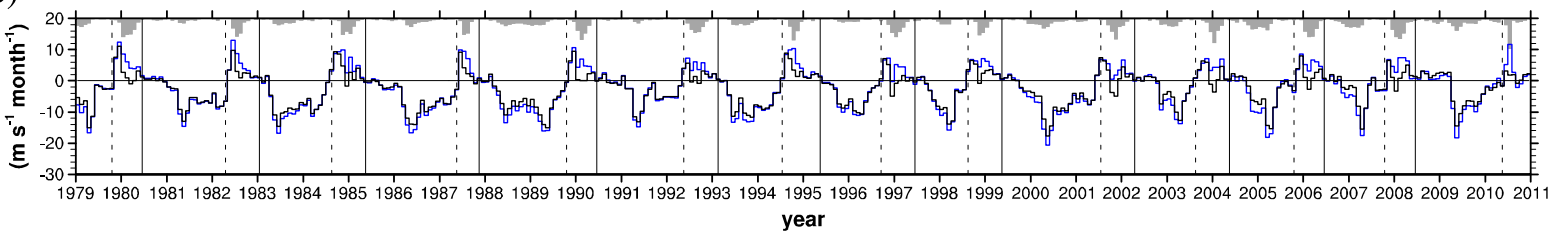

ERA-I - MERRA

CFSR

JRA-55

ERA-I ml

Figure 6. The same as in Fig. 2, except for the terms (a) $\bar{X}$, (b) $\bar{X}^{*}$, and (c) as in Fig. 3 for $\bar{X}^{*}$ (see the text for a definition of these terms).

Table 3. The same as in Table 2, except at $50 \mathrm{hPa}$.

\begin{tabular}{llllll}
\hline & \multicolumn{2}{c}{$\mathrm{E}-\mathrm{W}$} & & \multicolumn{2}{c}{ W-E } \\
\cline { 2 - 3 } \cline { 5 - 6 } & $p$-level & model-level & & $p$-level & model-level \\
\hline Kelvin & $\mathbf{2 . 7 - 6 . 8}$ & $\mathbf{4 . 6 - 9 . 2}$ & & & \\
MRG & $0.6-1.6$ & $0.6-1.7$ & & $0.6-2.3$ & $0.8-2.2$ \\
IG & $\mathbf{0 . 5 - 2 . 3}$ & $\mathbf{1 . 3 - 2 . 5}$ & & $0.4-2.4$ & $1.4-3.7$ \\
Rossby & $1.1-5.0$ & $1.3-3.6$ & & $0.7-4.0$ & $1.2-3.1$ \\
Net-resolved & $\mathbf{2 . 8 - 8 . 8}$ & $\mathbf{5 . 4 - 1 1}$ & & $0.9-6.4$ & $2.7-6.2$ \\
$\bar{X}$ & $\mathbf{3 . 7 - 1 0}$ & $\mathbf{2 . 2 - 4 . 3}$ & & $0.5-17$ & $6.9-13$ \\
$\bar{X}^{*}$ & $\mathbf{3 . 5 - 8 . 7}$ & & & $7.7-16$ & \\
\hline
\end{tabular}

near $10 \mathrm{hPa}$ in the reanalyses, owing to the vertical coverage of radiosonde observations. We additionally calculated the wave forcing estimates averaged over $10^{\circ} \mathrm{N}-10^{\circ} \mathrm{S}$ at $30 \mathrm{hPa}$ (Figs. S1-S3 in the Supplement). The results are generally similar with those for $5^{\circ} \mathrm{N}-5^{\circ} \mathrm{S}$ (Figs. 2, 3, 6), except that the Kelvin (MRG) wave forcing is about $31 \%(10-70 \%)$ smaller when averaged over $10^{\circ} \mathrm{N}-10^{\circ} \mathrm{S}$.

\section{Summary and discussions}

We have examined four reanalyses with the aim of estimating the momentum forcing of the QBO due to equatorial waves over the period 1979-2010. The temporal evolution of the forcing by equatorial wave modes is generally consistent between the reanalyses. The range of forcing by each wave mode is summarized in Tables 2-4. In the estimates for the $\mathrm{E}-\mathrm{W}$ phase using the $p$-level data sets from the four reanalyses, the Kelvin wave forcing at $30 \mathrm{hPa}(2.8-$ $8.7 \mathrm{~m} \mathrm{~s}^{-1} \mathrm{month}^{-1}$ ) was found to dominate the net wave forc-
Table 4. The same as in Table 2, except at $10 \mathrm{hPa}$.

\begin{tabular}{llllll}
\hline & \multicolumn{2}{c}{ E-W } & & \multicolumn{2}{c}{ W-E } \\
\cline { 2 - 3 } \cline { 5 - 6 } & $p$-level & model-level & & $p$-level & model-level \\
\hline Kelvin & $\mathbf{2 . 2 - 1 2}$ & $\mathbf{3 . 6}-\mathbf{- 1 5}$ & & & \\
MRG & $0.4-5.3$ & $0.2-3.6$ & & $0.4-2.3$ & $0.5-1.8$ \\
IG & $\mathbf{0 . 5}-\mathbf{4 . 9}$ & $\mathbf{2 . 7 - 6 . 2}$ & & $0.6-4.5$ & $2.7-5.9$ \\
Rossby & $0.7-8.0$ & $2.2-8.4$ & & $4.3-12$ & $6.1-14$ \\
Net-resolved & $\mathbf{2 . 8}-\mathbf{1 7}$ & $\mathbf{4 . 1 - 2 1}$ & & $6.2-15$ & $8.0-17$ \\
$\bar{X}$ & $\mathbf{5 . 5 - 3 1}$ & $\mathbf{4 . 7 - 1 6}$ & & $3.1-35$ & $5.9-25$ \\
$\bar{X}^{*}$ & $\mathbf{4 . 1 - 1 7}$ & & & $6.3-30$ & \\
\hline
\end{tabular}

ing resolved in the data sets $\left(3.4-11 \mathrm{~m} \mathrm{~s}^{-1} \mathrm{month}^{-1}\right)$. The forcing due to the MRG, IG, and Rossby waves in the WE phase was found to be small, with a net forcing of 1.5$5.2 \mathrm{~m} \mathrm{~s}^{-1} \mathrm{month}^{-1}$. The momentum forcing by processes that are not resolved in the reanalyses, which may be dominated by the mesoscale gravity waves, was also estimated. The unresolved forcing in the $\mathrm{E}-\mathrm{W}$ phase ranges from 5.8 to $14 \mathrm{~m} \mathrm{~s}^{-1}$ month $^{-1}$ and that in the W-E phase from 11 to $21 \mathrm{~m} \mathrm{~s}^{-1}$ month $^{-1}$.

The wave forcing was also calculated using the native model-level data from ERA-I. This calculation indicated that the Kelvin and IG wave forcing obtained from the $p$ level data sets was underestimated by at least $2-4$ and $1-$ $3 \mathrm{~m} \mathrm{~s}^{-1} \mathrm{month}^{-1}$, respectively. On the other hand, the unresolved forcing might be overestimated by a similar amount. Considering this, the net mesoscale gravity wave forcing of the QBO in the E-W phase would appear to be smaller than the Kelvin wave forcing, whereas in the W-E phase the gravity wave forcing is the dominant forcing term. 
There exist uncertainties in the resolved-scale waves in the reanalyses even for the model-level data. As discussed in Sect. 3.1, the substantial difference between the wave forcing from the model-level data and from the interpolated $p$-level data implies that a significant amount of waves with vertical wavelengths of about $2.8-5.6 \mathrm{~km}$ are present in the modellevel data. Given that these vertical wavelengths are at the lower bound of the ranges captured by the forecast models $\left(2 \Delta_{V}-4 \Delta_{V}\right)$, we can speculate that a substantial fraction of short-wavelength waves could remain under-represented in the reanalyses at the native model levels. The MRG and IG waves have vertical wavelengths that may be affected by this phenomenon. In a previous study by Ern et al. (2008), it was shown that the amplitudes of the MRG and IG waves in the ECMWF analysis are smaller than those from the SABER (Sounding of the Atmosphere using Broadband Emission Radiometry) observations. A number of studies using general circulation models (Boville and Randel, 1992; Giorgetta et al., 2006; Choi and Chun, 2008; Richter et al., 2014) have also demonstrated the need for high vertical resolutions $(500-700 \mathrm{~km})$ to capture equatorial waves; these are twice the resolution of the reanalyses used in this study.

There is another important source of uncertainty. The unresolved gravity wave forcing has been deduced from the other forcing terms in the zonal wind tendency equation. In the $\mathrm{W}-\mathrm{E}$ phase, the estimate of the unresolved forcing is highly dependent on the vertical advection term. However, as seen in Fig. 5a, the vertical velocity is poorly constrained in the reanalyses, and this introduces a large uncertainty in the vertical advection term. The spread in vertical advection between the reanalyses reaches $\sim 10 \mathrm{~m} \mathrm{~s}^{-1}$ month $^{-1}$. The validation of the vertical velocity field in the equatorial lower stratosphere in the reanalyses might be crucial for deducing the unresolved-scale wave contribution to the QBO (Ern et al., 2014).

\section{The Supplement related to this article is available online at doi:10.5194/acp-15-6577-2015-supplement.}

Acknowledgements. The authors would like to thank SeokWoo Son for providing the motivation for this work. The ERA-I data set was obtained from the ECMWF data server (http://apps.ecmwf.int/datasets/). The MERRA data set was provided by the Global Modeling and Assimilation Office at NASA Goddard Space Flight Center through the NASA GES DISC online archive. The CFSR data set was from NOAA's National Operational Model Archive and Distribution System which is maintained at NOAA's National Climatic Data Center. The JRA-55 data set was provided from the JRA-55 project carried out by the Japan Meteorological Agency. This study was funded by the Korea Meteorological Administration Research and Development Program under grant CATER 2012-3054.

Edited by: P. Haynes

\section{References}

Alexander, M. J. and Ortland, D. A.: Equatorial waves in High Resolution Dynamics Limb Sounder (HIRDLS) data, J. Geophys. Res., 115, D24111, doi:10.1029/2010JD014782, 2010.

Andrews, D. G., Holton, J. R., and Leovy, C. B.: Middle Atmosphere Dynamics, Academic, San Diego, California, 1987.

Aquila, V., Garfinkel, C. I., Newman, P. A., Oman, L. D., and Waugh, D. W.: Modifications of the quasi-biennial oscillation by a geoengineering perturbation of the stratospheric aerosol layer, Geophys. Res. Lett., 41, 1738-1744, doi:10.1002/2013GL058818, 2014.

Baldwin, M. P., Gray, L. J., Dunkerton, T. J., Hamilton, K., Haynes, P. H., Randel, W. J., Holton, J. R., Alexander, M. J., Hirota, I., Horinouchi, T., Jones, D. B. A., Kinnersley, J. S., Marquardt, C., Sato, K., and Takahashi, M.: The quasi-biennial oscillation, Rev. GeoPhys., 39, 179-229, 2001.

Boville, B. A. and Randel, W. J.: Equatorial waves in a stratospheric GCM: Effects of vertical resolution, J. Atmos. Sci., 49, 785-801, 1992.

Bushell, A. C., Jackson, D. R., Butchart, N., Hardiman, S. C., Hinton, T. J., Osprey, S. M., and Gray, L. J.: Sensitivity of GCM tropical middle atmosphere variability and climate to ozone and parameterized gravity wave changes, J. Geophys. Res., 115, D15101, doi:10.1029/2009JD013340, 2010.

Choi, H.-J. and Chun, H.-Y.: Effects of vertical resolution on a parameterization of convective gravity waves, Atmosphere, 18, 121-136, 2008.

Dee, D. P., Uppala, S. M., Simmons, A. J., Berrisford, P., Poli, P., Kobayashi, S., Andrae, U., Balmaseda, M. A., Balsamo, G., Bauer, P., Bechtold, P., Beljaars, A. C. M., van de Berg, L., Bidlot, J., Bormann, N., Delsol, C., Dragani, R., Fuentes, M., Geer, A. J., Haimberger, L., Healy, S. B., Hersbach, H., Hólm, E. V., Isaksen, L., Kållberg, P., Köhler, M., Matricardi, M., McNally, A. P., Monge-Sanz, B. M., Morcrette, J.-J., Park, B.-K., Peubey, C., de Rosnay, P., Tavolato, C., Thépaut, J.-N., and Vitart, F.: The ERA-Interim reanalysis: configuration and performance of the data assimilation system, Q. J. Roy. Meteorol. Soc., 137, 553597, doi:10.1002/qj.828, 2011.

Dunkerton, T. J.: The role of gravity waves in the quasibiennial oscillation, J. Geophys. Res., 102, 26053-26076, doi:10.1029/96JD02999, 1997.

Ern, M. and Preusse, P.: Wave fluxes of equatorial Kelvin waves and QBO zonal wind forcing derived from SABER and ECMWF temperature space-time spectra, Atmos. Chem. Phys., 9, 39573986, doi:10.5194/acp-9-3957-2009, 2009.

Ern, M., Preusse, P., Krebsbach, M., Mlynczak, M. G., and Russell III, J. M.: Equatorial wave analysis from SABER and ECMWF temperatures, Atmos. Chem. Phys., 8, 845-869, doi:10.5194/acp-8-845-2008, 2008.

Ern, M., Ploeger, F., Preusse, P., Gille, J. C., Gray, L. J., Kalisch, S., Mlynczak, M. G., Russell III, J. M., and Riese, M.: Interaction of gravity waves with the QBO: A satellite perspective, J. Geophys. Res., 119, 2329-2355, doi:10.1002/2013JD020731, 2014.

Evan, S., Alexander, M. J., and Dudhia, J.: WRF simulations of convectively generated gravity waves in opposite QBO phases, J. Geophys. Res., 117, D12117, doi:10.1029/2011JD017302, 2012.

Fels, S. B.: A parameterization of scale-dependent radiative damping rates in the middle atmosphere, J. Atmos. Sci., 39, 1141$1152,1982$. 
Garcia, R. R. and Salby, M. L.: Transient response to localized episodic heating in the tropics, Part II: Far-field behavior, J. Atmos. Sci., 44, 499-530, 1987.

Giorgetta, M. A., Manzini, E., and Roeckner, E.: Forcing of the quasi-biennial oscillation from a broad spectrum of atmospheric waves, Geophys. Res. Lett., 29, 1245, doi:10.1029/2002GL014756, 2002.

Giorgetta, M. A., Manzini, E., Roeckner, E., Esch, M., and Bengtsson, L.: Climatology and forcing of the quasi-biennial oscillation in the MAECHAM5 model, J. Climate, 19, 3882-3901, doi:10.1175/JCLI3830.1, 2006.

Hayashi, Y. and Golder, D. G.: United mechanisms for the generation of low- and high-frequency tropical waves, Part I: Control experiments with moist convective adjustment, J. Atmos. Sci., 54, 1262-1276, 1997.

Hilsenrath, E. and Schlesinger, B. M.: Total ozone seasonal and interannual variations derived from the 7 year Nimbus-4 BUV data set, J. Geophys. Res., 86, 12087-12096, 1981.

Holton, J. R. and Lindzen, R. S.: An updated theory for the quasibiennial cycle of the tropical stratosphere, J. Atmos. Sci., 29, 1076-1080, 1972.

Holton, J. R. and Tan, H.-C.: The influence of the equatorial quasibiennial oscillation on the global circulation at $50 \mathrm{mb}$, J. Atmos. Sci., 37, 2200-2208, 1980.

Kawatani, Y., Watanabe, S., Sato, K., Dunkerton, T. J., Miyahara, S., and Takahashi, M.: The roles of equatorial trapped waves and internal inertia-gravity waves in driving the quasi-biennial oscillation, Part I: Zonal mean wave forcing, J. Atmos. Sci., 67, 963-980, doi:10.1175/2009JAS3222.1, 2010a

Kawatani, Y., Watanabe, S., Sato, K., Dunkerton, T. J., Miyahara, S., and Takahashi, M.: The roles of equatorial trapped waves and internal inertia-gravity waves in driving the quasi-biennial oscillation, Part II: Three-dimensional distribution of wave forcing, J. Atmos. Sci., 67, 981-997, doi:10.1175/2009JAS3223.1, 2010 b.

Kawatani, Y., Lee, J. N., and Hamilton, K.: Interannual variations of stratospheric water vapor in MLS observations and climate model simulations, J. Atmos. Sci., 71, 4072-4085, doi:10.1175/JAS-D-14-0164.1, 2014.

Kim, Y.-H. and Chun, H.-Y.: Contributions of equatorial wave modes and parameterized gravity waves to the tropical QBO in HadGEM2, J. Geophys. Res., 120, 1065-1090, doi:10.1002/2014JD022174, 2015.

Kim, Y.-H., Bushell, A. C., Jackson, D. R., and Chun, H.-Y.: Impacts of introducing a convective gravity-wave parameterization upon the QBO in the Met Office Unified Model, Geophys. Res. Lett., 40, 1873-1877, doi:10.1002/grl.50353, 2013.

Kobayashi, S., Ota, Y., Harada, Y., Ebita, A., Moriya, M., Onoda, H., Onogi, K., Kamahori, H., Kobayashi, C., Endo, H., Miyaoka, K., and Takahashi, K.: The JRA-55 reanalysis: General specifications and basic characteristics, J. Meteorol. Soc. Jpn., 93, 5-48, doi:10.2151/jmsj.2015-001, 2015.

Krismer, T. R. and Giorgetta, M. A.: Wave forcing of the quasibiennial oscillation in the Max Planck Institute Earth System Model, J. Atmos. Sci., 71, 1985-2006, doi:10.1175/JAS-D-130310.1, 2014.

Li, K.-F. and Tung, K.-K.: Quasi-biennial oscillation and solar cycle influences on winter Arctic total ozone, J. Geophys. Res., 119, 5823-5835, doi:10.1002/2013JD021065, 2014.
Lindzen, R. S. and Holton, J. R.: A theory of the quasi-biennial oscillation, J. Atmos. Sci., 25, 1095-1107, 1968.

Maury, P. and Lott, F.: On the presence of equatorial waves in the lower stratosphere of a general circulation model, Atmos. Chem. Phys., 14, 1869-1880, doi:10.5194/acp-14-1869-2014, 2014.

Niwano, M., Yamazaki, K., and Shiotani, M.: Seasonal and QBO variations of ascent rate in the tropical lower stratosphere as inferred from UARS HALOE trace gas data, J. Geophys. Res., 108, 4794, doi:10.1029/2003JD003871, 2003.

Plumb, R. A. and Bell, R. C.: A model of the quasi-biennial oscillation on an equatorial beta-plane, Q. J. Roy. Meteorol. Soc., 108, 335-352, 1982.

Richter, J. H., Solomon, A., and Bacmeister, J. T.: On the simulation of the quasi-biennial oscillation in the Community Atmosphere Model, Version 5, J. Geophys. Res., 119, 3045-3062, doi:10.1002/2013JD021122, 2014.

Rienecker, M. M., Suarez, M. J., Gelaro, R., Todling, R., Backmeister, J., Liu, E., Bosilovich, M. G., Schubert, S. D., Takacs, L., Kim, G.-K., Bloom, S., Chen, J., Collins, D., Conaty, A., da Silva, A., Gu, W., Joiner, J., Koster, R. D., Lucchesi, R., Molod, A., Owens, T., Pawson, S., Pegion, P., Redder, C. R., Reichle, R., Robertson, F. R., Ruddick, A. G., Sienkiewicz, M., and Woollen, J.: MERRA: NASA's modern-era retrospective analysis for research and applications, J. Climate, 24, 3624-3648, doi:10.1175/JCLI-D-11-00015.1, 2011.

Rind, D., Jonas, J., Balachandran, N. K., Schmidt, G. A., and Lean, J.: The QBO in two GISS global climate models: 1, generation of the QBO, J. Geophys. Res., 119, 8798-8824, doi:10.1002/2014JD021678, 2014.

Saha, S., Moorthi, S., Pan, H.-L., Wu, X., Wang, J., Nadiga, S., Tripp, P., Kistler, R., Woollen, J., Behringer, D., Liu, H., Stokes, D., Grumbine, R., Gayno, G., Hou, Y.-T., Chuang, H., Juang, H.-M. H., Sela, J., Iredell, M., Treadon, R., Kleist, D., Delst, P. V., Keyser, D., Derber, J., Ek, M., Meng, J., Wei, H., Yang, R., Lord, S., van den Dool, H., Kumar, A., Wang, W., Long, C., Chelliah, M., Xue, Y., Huang, B., Schemm, J.-K., Ebisuzaki, W., Lin, R., Xie, P., Chen, M., Zhou, S., Higgins, W., Zou, C.-Z., Liu, Q., Chen, Y., Han, Y., Cucurull, L., Reynolds, R. W., Rutledge, G., and Goldberg, M.: The NCEP climate forecast system reanalysis, Bull. Am. Meteor. Soc., 91, 1015-1057, doi:10.1175/2010BAMS3001.1, 2010.

Salby, M. L. and Garcia, R. R.: Transient response to localized episodic heating in the tropics, Part I: near-field behavior, J. Atmos. Sci., 44, 458-498, 1987.

Sato, K., O'Sullivan, D. J., and Dunkerton, T. J.: Low-frequency inertia-gravity waves in the stratosphere revealed by three-week continuous observation with the MU radar, Geophys. Res. Lett., 24, 1739-1742, 1997.

Scaife, A. A., Butchart, N., Warner, C. D., Stainforth, D., Norton, W., and Austin, J.: Realistic Quasi-Biennial Oscillations in a simulation of the global climate, Geophys. Res. Lett., 27, 34813484, 2000.

Schirber, S., Manzini, E., and Alexander, M. J.: A convection-based gravity wave parameterization in a general circulation model: Implementation and improvements on the QBO, J. Adv. Model. Earth Syst., 6, 264-279, doi:10.1002/2013MS000286, 2014.

Schoeberl, M. R., Douglass, A. R., Stolarski, R. S., Pawson, S., Strahan, S. E., and Read, W.: Comparison of lower stratospheric 
tropical mean vertical velocities, J. Geophys. Res., 113, D24109, doi:10.1029/2008JD010221, 2008.

Schroeder, S., Preusse, P., Ern, M., and Riese, M.: Gravity waves resolved in ECMWF and measured by SABER, Geophys. Res. Lett., 36, L10805, doi:10.1029/2008GL037054, 2009.

Shibata, K. and Deushi, M.: Partitioning between resolved wave forcing and unresolved gravity wave forcing to the quasi-biennial oscillation as revealed with a coupled chemistry-climate model, Geophys. Res. Lett., 32, L12820, doi:10.1029/2005GL022885, 2005.
Skamarock, W. C., Park, S.-H., Klemp, J. B., and Snyder, C.: Atmospheric kinetic energy spectra from global high-resolution nonhydrostatic simulations, J. Atmos. Sci., 71, 4369-4381, doi:10.1175/JAS-D-14-0114.1, 2014.

Watson, P. A. G. and Gray, L. J.: How does the quasi-biennial oscillation affect the stratospheric polar vortex?, J. Atmos. Sci., 71, 391-409, doi:10.1175/JAS-D-13-096.1, 2014. 